\title{
曲げエネルギーを考慮した展開可能な曲面の設計支援
}

\author{
吉田 皓太郎 ${ }^{* 1}$, 若松 栄史 ${ }^{* 1}$ ，森永 英二*2，久保 貴裕 ${ }^{* 3}$
}

\section{Design support of a developable surface considering its bending energy}

\author{
Kotaro YOSHIDA ${ }^{* 1}$, Hidefumi WAKAMATSU*1 ${ }^{*}$ Eiji MORINAGA ${ }^{* 2}$ and Takahiro KUBO ${ }^{* 3}$ \\ ${ }^{* 1}$ Dept. of Materials and Manufacturing Science, Graduate School of Eng., Osaka University \\ 2-1 Yamadaoka, Suita-shi, Osaka 565-0871, Japan \\ ${ }^{* 2}$ Graduate School of Humanities and Sustainable System Sciences, Osaka Prefecture University \\ 1-1 Gakuen-cho, Naka-ku, Sakai-shi, Osaka 599-8531, Japan \\ ${ }^{* 3}$ Wacoal Holdings Corp. \\ 29 Nakajima-cho, Kisshoin, Minami-ku, Kyoto 601-8530, Japan
}

Received: 15 May 2020; Revised: 21 July 2020; Accepted: 24 August 2020

\begin{abstract}
A method to design a developable surface and its developed shape is proposed. A developable surface, which is generated by sweeping a straight line along a three-dimensional curve, can be seen many products such as ships, buildings, clothes, and so on. Although it is important to design the surface in case that designers give some constraints, its design process is not automated because of the difficulty of its modeling. Especially, cloth products are required to design not only their three-dimensional shapes but also their developed shapes. Therefore, we aim to propose a method to design the surface satisfying some constraints and its developed shape. As an example, we assume that some constraints are related to the control points of a curve in a developable surface. In this paper, it is revealed that the direction of a generatrix can be determined geometrically when a pair of three-dimensional curves are given. Moreover, in order to obtain a steadier shape, not only this condition but also the potential energy of the surface should be considered. From the above, we formulate optimization problems, upon this design process, which have different objective functions: one is the condition of a developable surface and the other is its bending energy. We compared and examined bending energies and maximum principal curvatures obtained by two different optimization problems. In order to verify our proposed method, we performed an experiment and confirmed its validity.
\end{abstract}

Keywords : Design, Modeling, Developable surface, Optimization, Automation

\section{1. 緒言}

伸縮させることなく平面に展開可能な曲面である可展面は，船体や建築物，衣類製品をはじめとして様々な工 業製品に用いられている．したがって，それらの曲面設計のために可展面のモデリングおよびその設計支援は重 要であると考えられている.また，多くの製品形状に見られる可展面は，ある平面を曲げて形成されることから， 曲面設計においてはその三次元形状だけでなく展開後の形状も重要である。したがって，曲面の三次元形状だけ でなく，その展開後の形状を包括的に設計支援することが求められる．過去には，離散的に可展面を取り扱う手 法 (Redont, 1989)，Bretrand 曲線群と呼ばれる，パラメータおよび曲線の主法線方向を互いに共有している曲線を 用いて表現する手法（Ravani and Ku, 1991, Bodduluri and Ravani, 1993）や制御点によって容易に曲線を操作可能な ベジエやスプライン曲線，曲面を用いて可展面を求める手法が提案されている（Aumann, 2003, Chu et al., 2008, Perez and Suarez, 2007)。しかしながら，あくまで曲面表現の方法に終始しており，展開後の形状まで導出する手 法に関しては求められていない。伊藤らはフレネ標構を用いてある三次元曲線の空間曲率と展開した後の曲線の

No.20-00169 [DOI:10.1299/transjsme.20-00169], J-STAGE Advance Publication date : 3 September, 2020

本論文は，第29回設計工学・システム部門講演会 講演論文集(2019), No. 2309の掲載内容に基づいた論文である.

*1 正員, 大阪大学 大学院工学研究科 マテリアル生産科学専攻 (†565-0871 大阪府吹田市山田丘 2-1)

$*_{2}$ 正員, 大阪府立大学 大学院人間社会システム科学研究科（テ599-8531 大阪府堺市中区学園町 1-1）

*3 (株) ワコール（广601-8530 京都府京都市南区吉祥院中島町 29）

E-mail of corresponding author: kotaro.yoshida@mapse.eng.osaka-u.ac.jp 
Yoshida, Wakamatsu, Morinaga and Kubo, Transactions of the JSME (in Japanese), Vol.86, No.891 (2020)

曲率から, 再現可能な可展面領域を求めている (伊藤, 今岡, 2007).この手法は, 展開形状と三次元形状の定量 的関係を示寸ことのできる手法ではあるが，形成可能な領域を示すだけなので直接的な可展面の設計は行うこと が難しい. また, フレネ標構はあくまで数学的な表現手法であり, 曲面の変形によるポテンシャルエネルギーを 考えることができない，そのようなエネルギーを考慮できるように，若松らは物体標構を用いた曲面モデルを提 案し，ブラジャーカップを対象にカップの型紙形状を与えた場合に，それらを立体的に組み立てた可展面形状を 求めている (Wakamatsu et al., 2017, 若松他， 2019). この手法はまた二次元形状の型紙と組み立てたあとの三次 元形状を定量的に結び付けるものであるが，意図する可展面形状を得るためにどのように型紙形状を設計すれば よいかまでは述べられていない, その中で, 我々はそのモデルを応用し, ブラジャーカップを対象に設計者が与 えた二本の曲線形状の間に形成される可展面形状およびその展開形状を最適化によって導出する手法を提案して いる（Yoshida et al., 2019）。この手法は，カップの三次元形状に関する特徵量を与えることによって，それを満た 寸可展面およびその展開形状を最適化によって直接設計することのできる手法である. しかし，与えた二つの曲 線が可展面を形成することを前提としていることから，二つの曲線の組み合わせが正しくない場合については， 最適化計算がうまく収束しない可能性がある，そこで，設計者が，二つの曲線ではなく，片方の曲線と，曲面に 関するいくつかの制約を与える場合を考え, 設計者が与えた制約を満たしかつ可展面形成を保証するようなもう 片方の曲線形状を設計する手法を構築することができれば, 曲面の設計作業において, より直感的に設計作業を することができると思われる. 本研究では, そのような可展面の設計が重要な製品として二枚接ぎブラジャーカ ップを対象に挙げる. ブラジャーカップには着用後のバストの形を美しくするなど, 様々な要求があり, その要 求にしたがって, パターンと呼ばれる布地を縫い合わせて構成している，その設計現場においては，設計者はま ず意図する製品の三次元形状を考え，その後それに合わせたパターン形状を考える．しかし，このパターン形状 はあくまで設計者の経験と勘に基づいて設計されるため, 実際にパターンを縫い合わせて製品を作る際, 設計者 の意図が製品形状に発現するかどうかは，パターンを設計した段階では分からない．したがって，紙で作ったパ ターンを組み立てて紙模型を作成し, 形状が意図通りであるかを確認しパターン形状を修正する．この一連の作 業が前述したように設計者の経験と勘に基づいて行われていることから, 設計現場では, その作業の効率化が求 められている，そこで本研究では，この設計作業における製品の紙模型を対象にし，設計者がその曲面が必ず通 過する点を指定したとき,そのときの可展面形状および展開した際の二次元形状を導出する手法について述べる.

\section{2. パターンのモデル化}

二枚接ぎブラジャーカップは下ワイヤー, 下カップ，上カップによって構成されており，下カップを形成する 型紙を下パターン，上カップを形成する型紙を上パターンと呼ぶ．また，下カップと上カップの接合線のことを 上下接ぎラインという．本研究では，二枚接ぎカップの下カップに注目し，下ワイヤーを与えた場合における対 応する上下接ぎラインを設計する. また，与える点として，図１に示すようなトップの位置を指定する作業を想 定する.

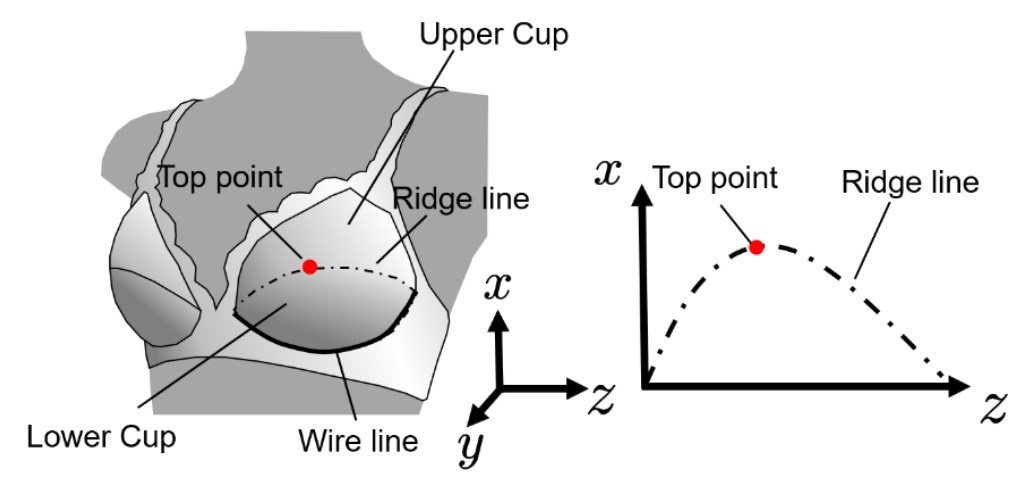

Fig.1 Expression of top point defined as the extreme value of the ridge line in $y z$-view. 
まず，下カップの変形形状の表現方法について述べる. 図 2 に示すようなパターン形状において，下ワイヤー と結合する稯線を下エッジ，上カップと結合する稜線を上エッジと呼ぶことにする，パターン形状は，この二つ のエッジによって構成されている. 下エッジに沿った距離を $s$, 下エッジの全長を $L_{L}$ とする. この下エッジ上に物 体標構 $P_{L}(s)-\xi_{L} \eta_{L} \zeta_{L}$ をとり， $\zeta_{L}$ を変位したエッジの接線方向に, $\eta_{L}$ 軸を変位したパターン曲面に対寸る法線方向 に常に一致するように設定する．また，パターンの二次元形状において，下エッジの始端を原点とし，これと終 端を結ぶ直線上に $v$ 軸, それと垂直な方向に $w$ 軸を設定する. 今, 下エッジの曲率を $\lambda_{L}(s), v$ 軸と軸のなす角度 を $\mu_{L}(s)$ とする.このとき， $\mu_{L}(s)$ は次式で表現できる.

$$
\mu_{\mathrm{L}}(\mathrm{s})=\mu_{\mathrm{L} 0}+\int_{0}^{s} \lambda_{\mathrm{L}} \mathrm{ds}
$$

ここで， $\mu_{\mathrm{L} 0}$ は $s=0$ における角度を表す.これを用いて型紙の平面座標值 $\mathrm{v}_{\mathrm{L}}$ およ゙゙ $\mathrm{w}_{\mathrm{L}}$ は次のように表される.

$$
\mathrm{v}_{\mathrm{L}}=\int_{0}^{\mathrm{s}} \cos \mu_{\mathrm{L}}(\mathrm{s}) \mathrm{d} \mathrm{s}, \mathrm{w}_{\mathrm{L}}=\int_{0}^{\mathrm{s}} \sin \mu_{\mathrm{L}}(\mathrm{s}) \mathrm{d} \mathrm{s}
$$

したがって, 下エッジの曲率 $\lambda_{\mathrm{L}}$ を求めることができれば, 式(1)〜(2)を使ってエッジ曲線の形状を求めることが できる.

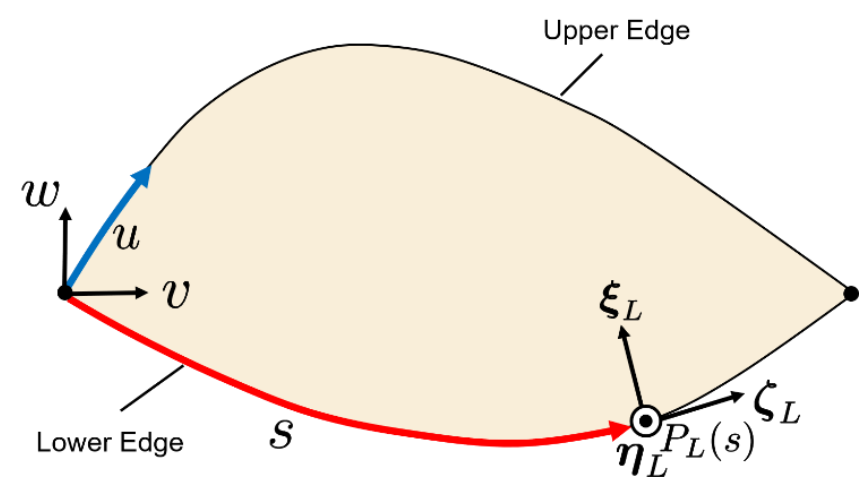

Fig.2 Object coordinates system on the lower edge: $\boldsymbol{\zeta}_{L}$ always coincides with the tangent vector of the lower edge, $\boldsymbol{\eta}_{L}$ is always coincides with the normal vector of the pattern surface, and $\xi_{L}=\boldsymbol{\eta}_{L} \times \zeta_{L}$.

また, 物体標構の各軸の変化量については, 剛体の運動における各軸回りの角速度とのアナロジーにより, 回 転率ベクトル $\omega_{\mathrm{L}}=\left[\begin{array}{lll}\omega_{\xi}^{L} & \lambda_{L} & \omega_{\zeta}^{L}\end{array}\right]$ を用いて以下の微分方程式が成立する.

$\left[\begin{array}{lll}\xi_{L}^{\prime} & \boldsymbol{\eta}_{L}^{\prime} & \zeta_{L}^{\prime}\end{array}\right]=\left[\begin{array}{lll}\xi_{L} & \boldsymbol{\eta}_{L} & \zeta_{L}\end{array}\right]\left[\begin{array}{ccc}0 & -\omega_{\zeta}^{L} & \lambda_{L} \\ \omega_{\zeta}^{L} & 0 & -\omega_{\xi}^{L} \\ -\lambda_{L} & \omega_{\xi}^{L} & 0\end{array}\right]=\left[\begin{array}{lll}\xi_{L} & \boldsymbol{\eta}_{L} & \zeta_{L}\end{array}\right] \Omega\left(\boldsymbol{\omega}_{L}\right)$

なお，以降ではsに関する微分をドット記号によって表現する。ここで，式(3)では $\eta_{L}$ 軸回りの回転率 $\omega_{\eta}^{L}$ は型紙 の曲率 $\lambda_{L}$ に相当することを利用している. この物体標構に対する微分方程式を解くことによって $s$ 対する各軸 の方向ベクトルを得ることができる. したがって, 下エッジ曲線の空間座標 $\boldsymbol{x}_{L}(s)=\left[\begin{array}{lll}x_{L}(s) & y_{L}(s) & z_{L}(s)\end{array}\right]^{\mathrm{T}}$ は式 (3)で求めた $\zeta_{\mathrm{L}}$ 積分することで求められる. ただし， $\boldsymbol{x}_{\mathrm{L} 0}$ は $s=0$ における位置を表す.

$$
\boldsymbol{x}_{\mathrm{L}}(\mathrm{s})=\boldsymbol{x}_{\mathrm{L} 0}+\int_{0}^{\mathrm{s}} \zeta_{\mathrm{L}} \mathrm{ds}
$$


次に，曲面論を用いた可展面の表現法について考える，一般的に，曲面は最大主曲率 $\kappa_{1}$ とその方向ベクトル $\boldsymbol{d}_{\mathbf{1}}$ および最小主曲率 $\kappa_{2}$ とその方向べクトル $\boldsymbol{d}_{2}$ によって表現することができる．また，曲面を特徴づける值としてガ

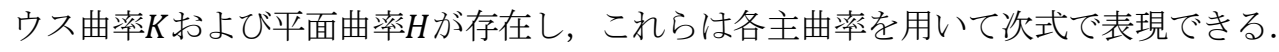

$$
\mathrm{K}=\kappa_{1} \kappa_{2}=\frac{\mathrm{LN}-\mathrm{M}^{2}}{\mathrm{EG}-\mathrm{F}^{2}}, \mathrm{H}=\frac{\kappa_{1}+\kappa_{2}}{2}=\frac{\mathrm{EN}-2 \mathrm{FM}+\mathrm{GL}}{2\left(\mathrm{EG}-\mathrm{F}^{2}\right)}
$$

ここで, $E, F, G$ は第一基本量, $L, M, N$ は第二基本量と呼ばれ, 物体標構を用いて計算すると次式のようになる.

$$
E=\zeta_{L} \cdot \zeta_{L}=1, F=\zeta_{L} \cdot \xi_{L}=0, G=\xi_{L} \cdot \xi_{L}=1, L=\zeta_{\mathrm{L}}^{\prime} \cdot \boldsymbol{\eta}_{L}=-\omega_{\xi}^{L}, M=\xi_{\mathrm{L}}{ }^{\prime} \cdot \boldsymbol{\eta}_{L}=\omega_{\zeta}^{L}
$$

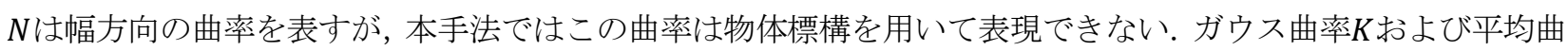
率 $H$ は，物体標構の各軸の回転率および $N$ を用いて次式で表現される.

$$
K=-\omega_{\zeta}^{L} N-\omega_{\xi}^{L}, H=\frac{-\omega_{\xi}^{L}+N}{2}
$$

ここで, 型紙は伸縮しないと仮定すると, 変形後のパターンの曲面は可展面となる. 可展面とは, 平面展開可

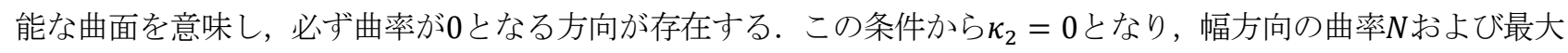
主曲率 $\kappa_{1}$ は次式で表される.

$$
N=-\frac{\omega_{\zeta}^{L^{2}}}{\omega_{\xi}^{L}}, \kappa_{1}=-\frac{\omega_{\zeta}^{L^{2}}+\omega_{\xi}^{L^{2}}}{\omega_{\xi}^{L}}
$$

この場合, 最小主曲率曲線は母線と呼ばれる直線を表し, このとき, 図 3 のように最大主曲率方向 $\boldsymbol{d}_{1}$ と $\zeta_{L}$ 軸と のなす角度 $\alpha_{L}$ をリブアングルと定義する．これを用いて主曲率方向 $\boldsymbol{d}_{1}$ および $\boldsymbol{d}_{2}$ は次式を用いて表される.

$$
\boldsymbol{d}_{1}=\zeta_{L} \cos \alpha_{L}+\xi_{L} \sin \alpha_{L}, \boldsymbol{d}_{2}=-\zeta_{L} \sin \alpha_{L}+\xi_{L} \cos \alpha_{L}
$$

以上より, 曲面には曲げとねじれが存在しているように思えるが，可展面であるという仮定を用いると，最大 主曲率方向 $\boldsymbol{d}_{1}$ に曲率 $\kappa_{1}$ の曲げ変形のみが起きているということが分かる. このとき， $\boldsymbol{\eta}_{\mathrm{L}}$ の変化量は主曲率方向の 成分しか持たないため, $\alpha_{L}$ と $\omega_{\xi}^{L}, \omega_{\zeta}^{L}$ との関係は次式で表現される.

$$
\omega_{\zeta}^{\mathrm{L}}=-\omega_{\xi}^{\mathrm{L}} \tan \alpha_{L}
$$

以上より, パターンの変形後の曲面形状は, 下エッジ上に定義される 3 つの変数 $\lambda_{L}, \omega_{\xi}^{\mathrm{L}}, \alpha_{L}$ を用いて求められる. 


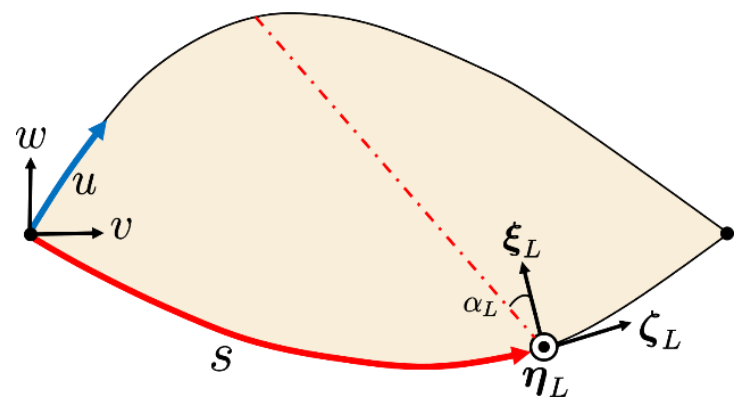

Fig.3 Definition of the rib angle $\alpha_{\mathrm{L}}$ between a direction of a generatrix and $\xi_{\mathrm{L}}$.

\section{3. 可展面形成条件の定式化}

今，下ワイヤーを表す空間座標ベクトル $\boldsymbol{x}_{\mathrm{LW}}(\mathrm{s})$ および上下接ぎラインを表す空間座標ベクトル $\boldsymbol{x}_{\mathrm{UW}}(u)$ をち る.ここで, $s, u$ はれぞれ曲線の弧長パラメータであり，また空間座標の弧長パラメータでの微分は二回までは 連続であるとする. すべてのsに対して対応するuを無作為に選び，そのときの点を結べば，その曲面は線織面と なる．線織面は可展面と同じようにある空間曲線とその点から伸びる直線べクトルによって定義され，その直線 ベクトル $\boldsymbol{q}(s, u)$ はそれぞれの弧長パラメータ $s, u か ゙$ 決まれば次のように表される.

$$
\boldsymbol{q}(\mathrm{s}, \mathrm{u})=\boldsymbol{x}_{\mathrm{UW}}(\mathrm{u})-\boldsymbol{x}_{\mathrm{LW}}(\mathrm{s})
$$

下ワイヤーに沿って微小距離 $d s$ 進んだ際, 上下接ぎラインに沿った距離がduだけ変化したとすると, 直線べク トルの変化量は次式で表現できる.

$$
\mathrm{d} \boldsymbol{q}=\frac{\partial \boldsymbol{q}}{\partial s} d s+\frac{\partial \boldsymbol{q}}{\partial u} d u=-\zeta_{\mathrm{LW}} d s+\zeta_{\mathrm{UW}} d u
$$

次に, 図 4 に示すように, 微小区間 $[s, s+d s],[u, u+d u]$ における微小曲面の構成要素を要素 $\boldsymbol{q}, \boldsymbol{\zeta}_{L W} d s, \boldsymbol{q}+$ $d \boldsymbol{q}, \boldsymbol{\zeta}_{U W} d u$ で囲まれる曲面 $\Theta$ と定義する. 線織面が可展面である場合, 母線が下ワイヤーおよび上下接ぎラインの 定義区間内に交差することなく存在する，つまりその場合微小曲面はそれぞれの辺が交差していない一つの平 面となる，この時，構成要素に関する条件から次式が求まる.

$$
\left(\zeta_{\mathrm{LW}} \times \zeta_{\mathrm{UW}}\right) \cdot \boldsymbol{q}=0
$$

この式の意味は, ある下ワイヤーに沿った弧長パラメータsに対し, 可展面ならば対応する上下接ぎラインの弧 長パラメータuが存在することを示している，つまり，弧長をパラメータとする上下接ぎラインの形状を一意に 決めたとき，sの定義域で式(13)を必ず満たすような関数 $u(s)$ が存在していることが可展面形成の条件となる．こ のことから，式(13)を全域で満たすためには，次式に示すVは最小化される必要がある.

$$
\mathrm{V}=\int_{0}^{\mathrm{L}_{\mathrm{L}}}\left|\left(\zeta_{\mathrm{LW}}(\mathrm{s}) \times \zeta_{\mathrm{UW}}(u(s))\right) \cdot \boldsymbol{q}(s)\right| d s
$$




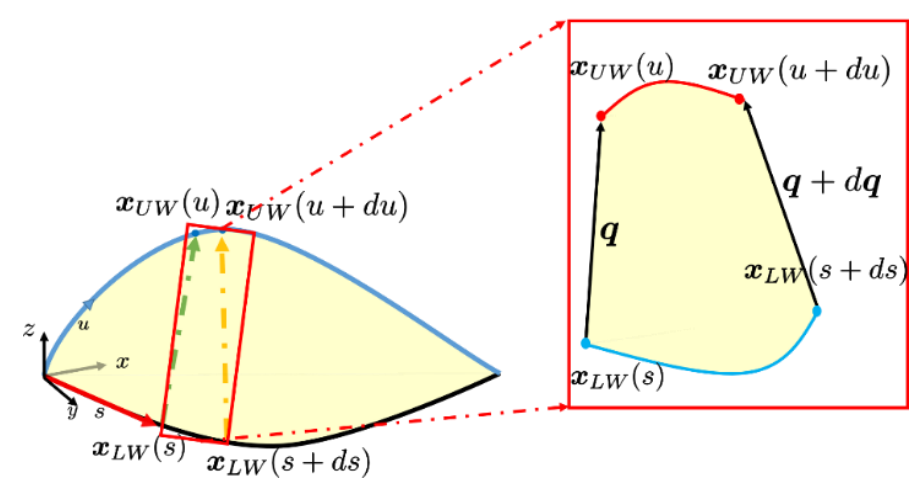

Fig.4 Definition of the components of the curved surface $\Theta$ composed of $\boldsymbol{q}, \boldsymbol{\zeta}_{\mathrm{LW}} d s, \boldsymbol{q}+d \boldsymbol{q}$ and $\boldsymbol{\zeta}_{U W} d u$.

次に, カップ形状に対する等式，不等式制約条件およびu(s)が与えられた場合における接ぎラインの表現方法 について考える．形状に関する制約としては，ある弧長岂に対して対応する制御点 $\boldsymbol{C}_{\mathrm{P}}$ 与゙ちえられているとき，制 約は次式のように表される.

$$
\boldsymbol{x}_{\mathrm{UW}}(\bar{u})=\boldsymbol{C}_{\mathrm{P}}
$$

本研究では, 二枚接ぎブラジャーカップの下カップを対象にしているため, 制御点 $\boldsymbol{C}_{\mathrm{P}}$ は下ワイヤーの終端およ び図 1 に示すトップの位置であるとする，トップの位置を対象にする際は, 式(15)の条件に加え, zy 平面に射影 された接ぎライン曲線が，トップの位置において極值をとることから次の不等式が成り立つ.

$$
\begin{array}{ll}
\zeta_{U}(u) \cdot \boldsymbol{e}_{y}>0 & \forall u \in[0, \bar{u}] \\
\zeta_{U}(u) \cdot \boldsymbol{e}_{y}<0 & \forall u \in\left[\bar{u}, \mathrm{~L}_{U}\right]
\end{array}
$$

ただし， $\boldsymbol{e}_{y}$ はy軸の単位べクトルを表している. また, 形状全域においてy座標が正であることを要求するため, 次式のような不等式を満たす必要がある.

$$
\boldsymbol{x}_{\mathrm{UW}}(\mathrm{u}) \cdot \boldsymbol{e}_{\mathrm{y}}>0 \quad \forall u \in\left[0, \mathrm{~L}_{\mathrm{U}}\right]
$$

また，回転率ベクトルに関する制約として， ろU 回りの回転率はその形状に影響を与えないため， $\omega_{\zeta}^{\mathrm{U}} \equiv 0$ として 考えることができる．u(s)に関する制約については，まず弧長であることから次のことが成り立つ.

$$
\mathrm{u}>0 \quad \forall \mathrm{s} \in\left[0, \mathrm{~L}_{\mathrm{L}}\right]
$$

また，母線が交差することを避けるため次式が成立する.

$$
u^{\prime}>0 \quad \forall s \in\left[0, \mathrm{~L}_{\mathrm{L}}\right]
$$


式(19),(20)の制約は，適当な関数f(s)を用いて表現してやることで，式を自動的に満たすようにする.

$$
u^{\prime}=\{f(s)\}^{2}, u=\int_{0}^{s}\{f(s)\}^{2} d s
$$

任意の関数 $\mathrm{g}(\mathrm{u})$ と $\mathrm{u}(\mathrm{s})$ の合成関数を $\mathrm{g}(\mathrm{s})$ と表現する. このとき, 接ぎライン形状における物体標構の微分方程式 は次式のように表される。

$$
\left[\begin{array}{lll}
\tilde{\xi}_{U}^{\prime} & \widetilde{\boldsymbol{\eta}}_{U}^{\prime} & \tilde{\zeta}_{U}^{\prime}
\end{array}\right]=u^{\prime}\left[\tilde{\xi}_{U} \quad \widetilde{\boldsymbol{\eta}}_{U} \quad \tilde{\zeta}_{U}\right] \Omega\left(\widetilde{\boldsymbol{\omega}}_{U}\right)
$$

これをsに対する微分方程式とみて解けば，sに対応する物体標構を得ることができる，そして，その空間座標 $\tilde{\boldsymbol{x}}_{U}(\mathrm{~s})$ は次式のように計算される.

$$
\tilde{\boldsymbol{x}}_{\mathrm{U}}(\mathrm{s})=\int_{0}^{s} \tilde{\zeta}_{U} u^{\prime} d s
$$

以上より，立体形状の持つ制約を満たす可展面およびその展開形状の設計は，設計変数はuを表現するf(s)および

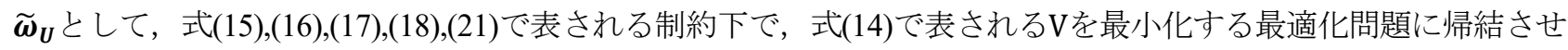
ることができる.本手法では, 設計変数を Ritz法により基底関数の重みつき線形和として次式のように表現する.

$$
\mathrm{f}(\mathrm{s})=\sum_{i=0}^{n_{u}} a_{i}^{u} e_{i}(s), \widetilde{\omega}_{\xi}=\sum_{i=0}^{n_{\xi}} a_{i}^{\xi} e_{i}(s), \widetilde{\omega}_{\eta}=\sum_{i=0}^{n_{\eta}} a_{i}^{\eta} e_{i}(s)
$$

基底関数に関しては，次式に示すような周期の異なる三角関数を用いた.

$$
e_{i}=\left\{\begin{array}{c}
1 \quad(i=0) \\
\frac{1}{L_{L}} s \quad(i=1) \\
\sin \left(\frac{\mathrm{i} \pi}{\mathrm{L}_{\mathrm{L}}} \mathrm{s}\right) \quad(\mathrm{i}=2 \mathrm{k}) \\
\cos \left(\frac{\mathrm{i} \pi}{\mathrm{L}_{\mathrm{L}}} \mathrm{s}\right) \quad(\mathrm{i}=2 \mathrm{k}+1) \quad(\forall \mathrm{k} \in \mathrm{N})
\end{array}\right.
$$

以上により, 最適化問題は, 曲線の初期姿勢を加えた係数ベクトル $\boldsymbol{a}=\left[\begin{array}{llllll}\boldsymbol{a}^{u} & \boldsymbol{a}^{\xi} & \boldsymbol{a}^{\eta} & \boldsymbol{\xi}_{U}^{0} & \boldsymbol{\eta}_{U}^{0} & \boldsymbol{\zeta}_{U}^{0}\end{array}\right]$ に関する非 線形計画問題一と変換することができ，適当な手法を用いて解くことができる.

次に, 曲線の形状および弧長間の関係 $u(\mathrm{~s})$ が得られた場合の型紙形状導出過程を示寸. 式(11)で表される直線べ クトル $\boldsymbol{q}(\mathrm{s}, \mathrm{u})$ は可展面における母線に相当するため, リブアングル $\alpha_{\mathrm{L}}$ は次式のようになる.

$$
\alpha_{\mathrm{L}}=\sin ^{-1}\left(-\frac{q}{|q|} \cdot \zeta_{\mathrm{L}}\right)
$$

ただし， $\zeta_{\mathrm{L}} \equiv \zeta_{\mathrm{LW}}$ としている．また， $d_{2}=\boldsymbol{q} /|\boldsymbol{q}|$ となるため，式(3)および(9)により， $\xi_{\mathrm{L}}$ および型紙の平面曲 率 $\lambda_{L}$ は次式のように表される. 
$\xi_{\mathrm{L}}=\frac{\boldsymbol{q}}{|\boldsymbol{q}| \cos \alpha_{\mathrm{L}}}+\zeta_{\mathrm{L}} \tan \alpha_{\mathrm{L}}, \lambda_{\mathrm{L}}=\zeta_{\mathrm{L}}^{\prime} \cdot \frac{\boldsymbol{q}}{|\boldsymbol{q}| \cos \alpha_{\mathrm{L}}}$

あとは，式(1)〜(2)を用いることでパターンの下エッジ形状を得ることができる.

次に，上エッジの求め方について述べる. 平面型紙上の母線方向ベクトル $\boldsymbol{q}_{\mathrm{E}}=\left[\begin{array}{ll}v_{E} & w_{E}\end{array}\right]^{T}$ は, 下エッジの接線 ベクトル $\zeta_{\mathrm{LE}}=\left[\begin{array}{ll}\cos \mu_{\mathrm{L}} & \sin \mu_{\mathrm{L}}\end{array}\right]^{T}$ そ $\eta_{\mathrm{LE}}$ 軸回りに $\pi / 2+\alpha_{\mathrm{L}}$ だけ回転させることで求めることができ, 次式で表され る.

$$
\boldsymbol{q}_{\mathrm{E}}=\left[\begin{array}{l}
\cos \left(\frac{\pi}{2}+\alpha_{L}-\mu_{L}\right) \\
\sin \left(\frac{\pi}{2}+\alpha_{L}-\mu_{L}\right)
\end{array}\right]
$$

あとは，この母線方向に長さ $|\boldsymbol{q}|$ だけ伸ばすことで，上エッジの形状を求めることができ，型紙全体の形状を求 めることができる.

\section{4. 可展面条件を目的関数とした場合の計算結果}

本章では, 図 1 に示寸トップの位置を変更した場合における数值計算例をそれぞれ求め, その傾向から手法の 妥当性を確認する. 下ワイヤーの形状は次式の $\omega_{\mathrm{L}}$ にって与えた.

$$
\boldsymbol{\omega}_{\mathrm{L}}=\left[\begin{array}{lll}
0 & 2.917 & 0
\end{array}\right]
$$

このときのトップの位置ベクトル $\boldsymbol{C}_{\mathrm{P}}$ を指定した場合における三次元曲線の形状およびそのときの型紙を，図 5 に示す.

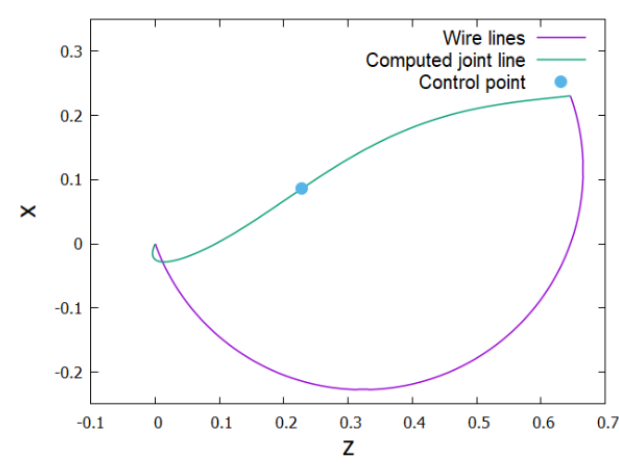

(a) from z-y plane

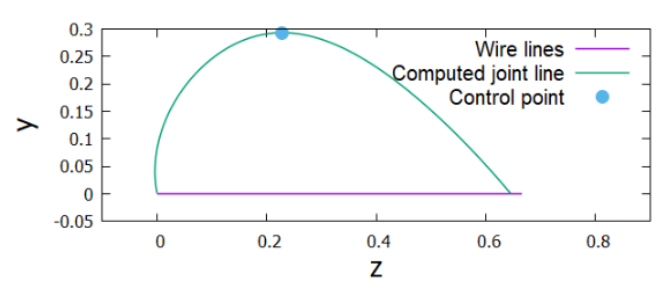

(b) from z-x plane 


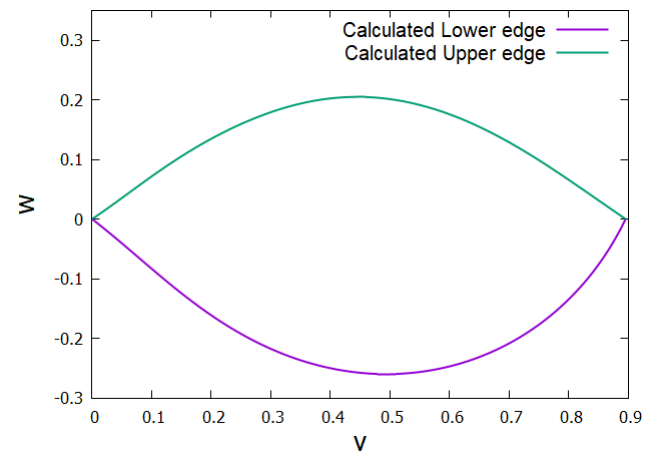

(c) The pattern calculated by our proposed method

Fig.5 The simulation result in case $\boldsymbol{C}_{P}=\left[\begin{array}{lll}0.228 & 0.086 & 0.293\end{array}\right]$ with its condition of a developable surface minimized: a violet line represents the given wire line, a green line represents the optimized, and a blue dot is the given control point in (a) and (b). In (c), a violet line represents the calculated lower edge and a green line represents the calculated upper edge.

図 5 の(a),(b)において，紫線が与えた下ワイヤーを指し，緑線が計算された上下接ぎラインを指す．また，与え た制御点を水色点によって表現している. (c)については，柴線が下エッジ，緑線が上エッジをそれぞれ示してい る. 各形状について，それぞれ制約条件として与えた制御点を通ることが確認され，それに対応して主に上エッ ジ形状が大きく変化していることが分かる．したがって，これらのことから，制御点を通る上下接ぎラインとそ のときの展開形状を得ることができることが確認できた.

\section{5. 曲面の曲げエネルギーを考慮した設計支援手法}

式(14)を目的関数とする最適化問題は，係数ベクトルaに対し， $V\left(\boldsymbol{a}^{*}\right)=0$ を満たす解ベクトル $\boldsymbol{a}^{*}$ を，数学的に 解くことに等しいが，その解ベクトル $\boldsymbol{a}^{*}$ は唯一定まるとは限らず，複数の解が存在する場合もあり，その場合に おいては，式(14)を目的関数とする最適化問題において得られる解は，その複数のうちの一つを求めているにす ぎないと考えられる，その場合，複数ある解のうち，どの解が適切であるかを考える必要がある。ここで，これ までの議論においては，あくまで曲面を数学的に取り扱っているが，実際の曲面は，その曲げ・ねじれに応じた ひずみおよび応力が発生する。曲げ・ねじれが大きい形状を形成すれば，その分ひずみや応力が大きいものとな ってしまい，結果として曲面への負荷が大きくなってしまう。ここで，曲面の曲げ・ねじれ量は，それぞれによ って生じるポテンシャルエネルギーによって評価することができることから，本研究では，解の適切さを曲面の 持つポテンシャルエネルギーの大小によって評価し，曲げ・ねじれ量がなるべく少なくなるような可展面形状の 設計を支援する手法について考える.

可展面の持つポテンシャルエネルギーについて述べる．２章で述べているように，可展面においては最大主曲 率方向に曲がっているのみであると考えることができるため，曲げエネルギーのみを考慮すればよい，可展面の 任意な空間座標 $\boldsymbol{X}(s, t)$ は，ある可展面上に存在する基準曲線の空間座標 $\boldsymbol{p}(s)$ および母線方向べクトル $\boldsymbol{q}(s)$ を用い $\tau \boldsymbol{X}(s, t)=\boldsymbol{p}(s)+t \boldsymbol{q}(s)$ と表現される. $\boldsymbol{p}(s)$ を式(5)の $\boldsymbol{x}_{\boldsymbol{L}}(s)$ に, $\boldsymbol{q}(s)$ を $\boldsymbol{d}_{2}$ に対応させて考えるとき，任意の空間座 標值 $\boldsymbol{X}(s, t)$ における, 最大主曲率 $\hat{\kappa}_{1}(s, t)$ について求める. このとき, 可展面を図 6 のような微小区間で見るとき, この区間においては，ある円錐の側面部の一部として扱うことができる.このときの円錐の母線最大長を $\mathrm{T}(\mathrm{s})$ と おけば，相似の関係より， $\widehat{\kappa}_{1}(s, t)$ を以下の式で表現できる.

$$
\widehat{\kappa}_{1}=\frac{T}{T-t} \kappa_{1}
$$

ここで，図 6 に示す関係性より，Tに関する近似式として 


$$
T\left(d \alpha_{L}+\lambda_{L} d s\right)=d s \cos \alpha_{L}
$$

を得る. 式(31)を式(30)に代入することで $\hat{\kappa}_{1}(s, t)$ は

$$
\widehat{\kappa}_{1}=\frac{\cos \alpha_{L}}{\cos \alpha_{L}-t\left(\alpha_{L}^{\prime}+\lambda\right)} \kappa_{1}
$$

と求めることができる.

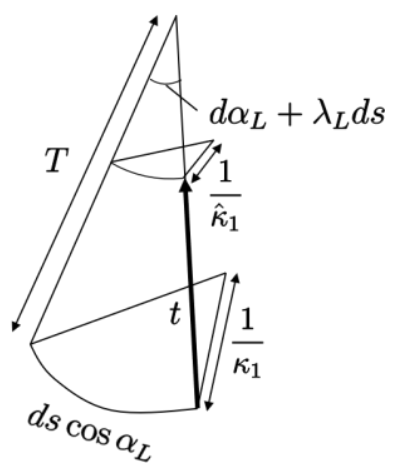

Fig.6 The relationship between $\kappa_{1}$ and $\hat{\kappa}_{1}$ : assuming that a minimum area of a developable surface is a part of a cone surface.

この $\hat{\kappa}_{1}(s, t)$ を用いて可展面のポテンシャルエネルギーは

$$
\mathrm{U}=\frac{\mathrm{R}_{\mathrm{f}}}{2} \int_{\mathrm{S}} \hat{\kappa}_{1}^{2} d S=\frac{\mathrm{R}_{\mathrm{f}}}{2} \iint_{\mathrm{S}, \mathrm{t}} \hat{\kappa}_{1}^{2}\left|\boldsymbol{X}_{\boldsymbol{s}} \times \boldsymbol{X}_{t}\right| d s d t
$$

と表される．ただし，下付き文字はその变数で偏微分していることを表しており， $\mathrm{R}_{\mathrm{f}}$ はパターンの曲げ剛性を表 す. $\boldsymbol{X}(s, t)$ の, $t$ に関する偏微分はそれぞれ $\boldsymbol{X}_{s}=\zeta_{L}-t\left(\alpha_{L}^{\prime}+\lambda_{L}\right) \boldsymbol{d}_{1}, \boldsymbol{X}_{\mathrm{t}}=\boldsymbol{d}_{2}$ であることから, $\boldsymbol{X}_{\boldsymbol{s}} \times \boldsymbol{X}_{t}$ は次式の ように計算される.

$$
\boldsymbol{X}_{\boldsymbol{s}} \times \boldsymbol{X}_{t}=\left(\cos \alpha_{L}-t\left(\alpha_{L}^{\prime}+\lambda_{L}\right)\right) \boldsymbol{\eta}_{L}
$$

以上から，ポテンシャルエネルギーは次式によって計算できる.

$$
\mathrm{U}=\frac{\mathrm{R}_{\mathrm{f}}}{2} \int_{0}^{L_{L}} \frac{\kappa_{1}^{2} \cos ^{2} \alpha_{L}}{\alpha^{\prime}{ }^{\prime}+\lambda_{L}} \log \left|\frac{\cos \alpha_{L}}{\cos \alpha_{L}-t\left(\alpha_{L}^{\prime}+\lambda_{L}\right)}\right| d s
$$

以上より，4 章で述べた設計者の与えた制約を満たしつつ，なるべく曲がり量の少ない可展面およびその展開形 状は，3 章と同様に，設計変数はuを表現する $\mathrm{f}(\mathrm{s}) お よ ひ ゙ \widetilde{\boldsymbol{\omega}}_{U}$ として，式(35)で求められたポテンシャルエネルギー を，3章で示した等式・不等式制約に式(14)を等式制約として加えた最適化問題に帰結させることがでさる.この 
最適化問題もまた, $\mathrm{f}(\mathrm{s}) お よ ひ ゙ \widetilde{\boldsymbol{\omega}}_{U}$ を Ritz 法で基底関数の線形和で表現したのち, 非線形計画法を用いて解くこと ができる.

\section{6. 曲面の曲げエネルギーを目的関数とした計算結果および計測実験}

本章では，図 1 に示すトップの位置 $\boldsymbol{C}_{\mathrm{P}}$ を $\boldsymbol{C}_{P}=\left[\begin{array}{lll}0.228 & 0.086 & 0.293\end{array}\right]$ として，5 章の最適化計算を行ったそその とき得られた曲線形状および曲面形状を図 7 に示す。なお，下ワイヤー形状は 4 章で用いたものと同じものを用 いており，式(35)における $\mathrm{R}_{\mathrm{f}}$ は $\mathrm{R}_{\mathrm{f}}=10$ として与えている.

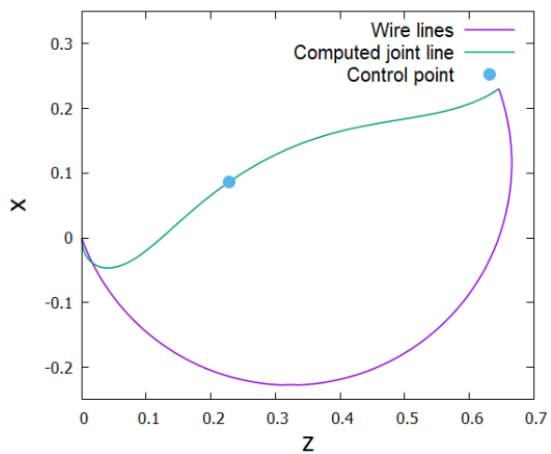

(a) from z-y plane

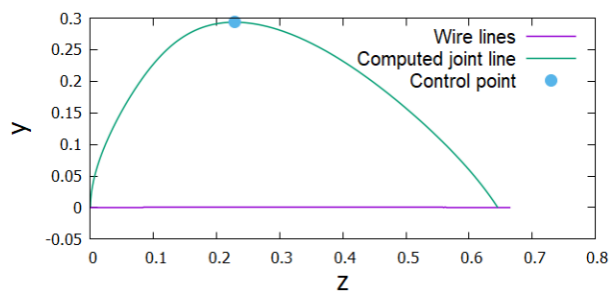

(b) from z-x plane

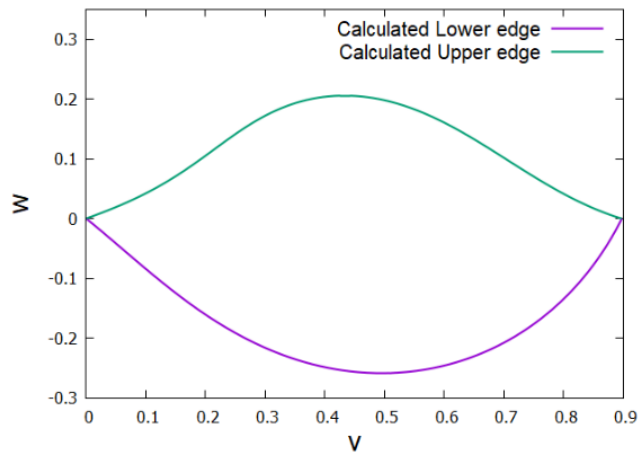

(c) The pattern calculated by our proposed method

Fig.7 The simulation result in case $\boldsymbol{C}_{P}=\left[\begin{array}{lll}0.228 & 0.086 & 0.293\end{array}\right]$ with its bending energy minimized: a violet line represents the given wire line, a green line represents the optimized, and a blue dot is the given control point in (a) and (b). In (c), a violet line represents the calculated lower edge and a green line represents the calculated upper edge.

可展面条件 $\mathrm{V}$ 目的関数として得られた結果およびポテンシャルエネルギーUを目的関数として得られた結果 のポテンシャルエネルギーおよび最大主曲率の最大值を比較する。なお，最大主曲率の最大值は以下のように求 めている.

$$
\kappa_{1}^{\max }=\max _{s} \max _{t} \hat{\kappa}_{1}
$$


Yoshida, Wakamatsu, Morinaga and Kubo, Transactions of the JSME (in Japanese), Vol.86, No.891 (2020)

Table 1 The comparison between different objective functions: comparing the potential energy and the maximum value of the maximum principal curvature in case that objective function is bending energy of the developable surface with that objective function is the condition of the developable surface.

\begin{tabular}{|l|c|c|}
\hline \multicolumn{1}{|c|}{ Objective function } & $\begin{array}{c}\text { Case: objective function is bending energy of } \\
\text { the developable surface }\end{array}$ & $\begin{array}{c}\text { Case: objective function is the } \\
\text { condition of the developable surface }\end{array}$ \\
\hline $\begin{array}{l}\text { Potential energy of the developable } \\
\text { surface }\end{array}$ & 11.87 & 13.43 \\
\hline $\begin{array}{l}\text { Maximum value of the maximum } \\
\text { principal curvature }\end{array}$ & 5.212 & 9.083 \\
\hline
\end{tabular}

また，目的関数を変えた場合におけるワイヤーの弧長sに対する主曲率 $\kappa_{1}$ の分布を, 図 8 に示す.

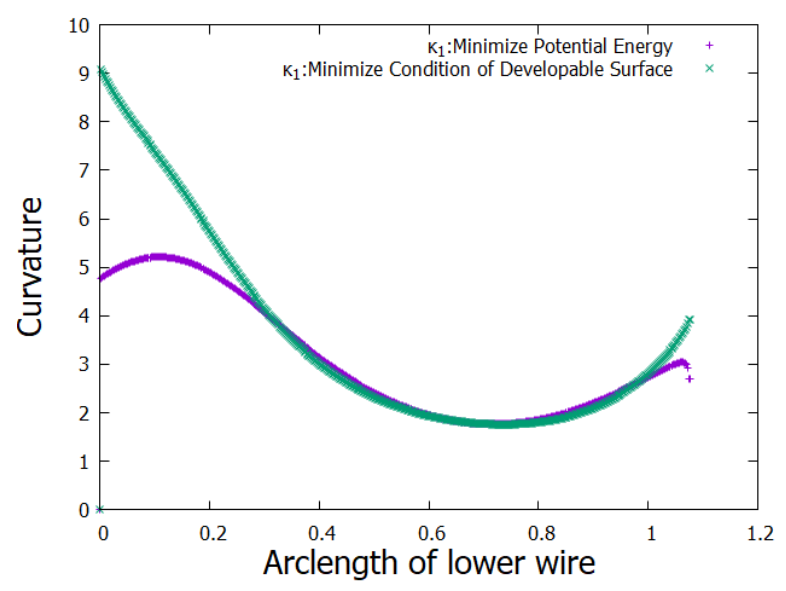

Fig.8 The comparison of $\kappa_{1}^{\max }$ between two different objective functions: a violet line represents the result in case that objective function is bending energy of the surface, and a green line represents the result in case that objective function is the condition of developable surface.

表 1 の結果より，Uを目的関数とした場合，Vを目的関数とした場合に比べてポテンシャルエネルギーは $13.09 \%$ ほど減少し，最大主曲率の最大值は，74.21\%ほど減少した結果となった。 また，図 8 で得られたグラフを考察す ると，特に始端および終端部分で大きく差が開いており，それ以外の部分ではほとんど同じ分布になっている. これらの結果から，Uを目的関数とした方が，得られた曲面形状において，局所的な曲がり具合が少なくなり，ポ テンシャルエネルギーがより小さい曲面形状および展開形状を得ることができたと結論づける.

最後に，その得られた型紙が三次元形状を再現することを確かめるため，計測実験を行い，本手法の妥当性を 確認する. 実験の概要としては, 図 7(c)に示した展開形状から紙模型を作成, その後その紙模型を 3D スキャナ により計測し, 得られた上下接ぎラインを元のシミュレーションによって得られた接ぎラインと比較することに よって確かめた。 その比較図を図 9 に示す.

紫の線が元々のワイヤー形状に相当し, 緑の線がシミュレーションにより得られた曲線形状に相当する.また, 水色の点は計測によって得られた曲線形状を表している.シミュレーションと実験における誤差の最大值は曲面 の法線方向に $2.6 \%$ あった。この結果から，本手法で得られた型紙形状は三次元形状を再現することを確かめる ことができ，実世界においても適用可能な手法であることを示せたと考える. 


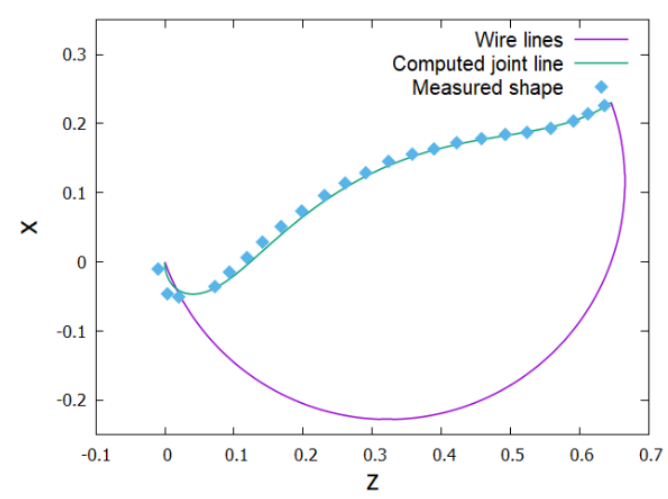

(a) from z-y plane

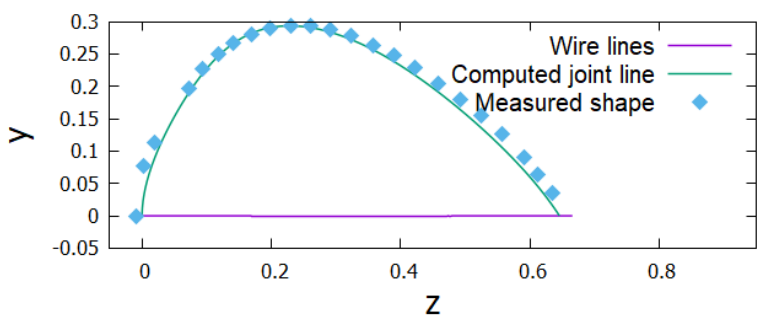

(b) from z-x plane

Fig.9 The comparison between computed and measured shape: a violet line represents the given wire line, a green line represents the optimized, and a blue dot is the measured ridge line in (a) and (b).

\section{7. 結}

本研究では，可展面の設計支援を目標に，与えた曲線に対応する曲線において，制御点が与えられた場合にお ける可展面およびパターンの二次元形状を自動導出する手法を提案した.まず，微分幾何学を用いて型紙の変形 形状をモデリングし，その後，幾何学的アプローチを用いて，下ワイヤーと上下接ぎラインの情報から型紙形状 を導出する過程を示した。その上で，可展面形成条件を目的関数とし，弧長間の関係および曲線形状を決定する 変数を設計変数にする最適化問題に帰結できることを示した．次に，この手法を拡張し，現実世界への適用を考 え，可展面形成条件を制約条件として，目的関数を曲げにより発生するポテンシャルエネルギーとした最適化問 題を定式化した. 最後に，二つの目的関数における主曲率とポテンシャルエネルギーを比較すると共に，得られ た型紙の再現性を確かめるために, 計測実験を行って, 妥当性を評価した。 以上の結果から, 本手法は, 可展面 設計の効率化を目的とし, 微分幾何学に基づいたモデルにより, 可展面設計支援手法を提案することができたと 結論づける，今後は，位置的な制約だけでなく，様々な制約を与えた場合や，曲面の伸びや圧縮を考慮した設計 支援に拡張していきたいと考える.

\section{文献}

Aumann, G., A simple algorithm for designing developable bezier surfaces, Computer aided geometrix Design, Vol.20(2003), pp.601-619.

Bodduluri, R.M.C. and Ravani, B., Design of developable surfaces using duality between plane and point geometries, Computer-Aided Design, Vol.25(1993), pp.621-632.

Chu, C.-H., Wang, C. C. L. and Tsai, C.-R., Computer aided geometric design of strip using developable bezier patches, Computers in Industry, Vol.59(2008), pp.601-611.

伊藤海織, 今岡春樹, 可展面理論を用いた縫合後の形状予測と縫合可能性, 繊維製品消費科学, Vol.48, No.1 (2007), pp.42-51.

Perez, F. and Suarez, J.A., Quasi-developable b-spline surfaces in ship hull design, Computer-Aided Design, Vol.39, No.10 (2007), pp.852-862.

Ravani, B. and Ku, T.S., Bertrand offsets of ruled and developable surfaces, Computer-Aided Design, Vol.23(1991), pp.145152.

Redont, P., Representation and deformation of developable surfaces, Computer-Aided Design, Vol.21, No.1 (1989), pp.13-20.

Solomon, J., Vouga, E., Wardetzky, M. and Grinspun, E., Flexible developable surfaces, Computer Graphics Forum, Vol.33(2012), pp.1567-1576.

Wakamatsu, H., Morinaga, E., Arai, E. and Kubo, T., A virtual paper model of a three piece brassiere cup to improve the efficiency of cup design process, Proceeding of IEEE International Conference on Robotics and Automation (ICRA)(2017), pp. 1169-1174.

若松栄史, 吉田皓太郎, 森永英二, 荒井栄司, 久保貴裕, ブラジャーカップの設計支援のための紙模型の三次元形 
状予測＼cjkstart第一報：2 枚接ぎカップへの適用, Journal of Textile Engineering, Vol. 65, No. 3(2019), pp. 35-46.

Yoshida, K., Wakamatsu, H., Morinaga, E., Arai, E., Tsutsumi, S. and Kubo, T., Pattern shape optimization of a two-piece brassiere cup to improve its design efficiency，システム制御情報学会論文誌, Vol. 32, No. 5(2019), pp. 192-202.

\section{References}

Aumann, G., A simple algorithm for designing developable bezier surfaces, Computer aided geometrix Design, Vol.20(2003), pp.601-619.

Bodduluri, R.M.C. and Ravani, B., Design of developable surfaces using duality between plane and point geometries, Computer-Aided Design, Vol.25(1993), pp.621-632.

Chu, C.-H., Wang, C. C. L. and Tsai, C.-R., Computer aided geometric design of strip using developable bezier patches, Computers in Industry, Vol.59(2008), pp.601-611.

Itoh, M. and Imaoka, H., A method of prediction sewn shapes and a possibility of sewing by theory of developable surfaces, The Japan Research Association for Textile End-Uses, Vol.48, No.1 (2007), pp.42-51 (in Japanese).

Perez, F. and Suarez, J.A., Quasi-developable b-spline surfaces in ship hull design, Computer-Aided Design, Vol.39, No.10 (2007), pp.852-862.

Ravani, B. and Ku, T.S., Bertrand offsets of ruled and developable surfaces, Computer-Aided Design, Vol.23(1991), pp.145152.

Redont, P., Representation and deformation of developable surfaces, Computer-Aided Design, Vol.21, No.1 (1989), pp.13-20.

Solomon, J., Vouga, E., Wardetzky, M. and Grinspun, E., Flexible developable surfaces, Computer Graphics Forum, Vol.33(2012), pp.1567-1576.

Wakamatsu, H., Morinaga, E., Arai, E. and Kubo, T., A virtual paper model of a three piece brassiere cup to improve the efficiency of cup design process, Proceeding of IEEE International Conference on Robotics and Automation (ICRA)(2017), pp. 1169-1174.

Wakamatsu, H., Yoshida, K., Morinaga, E., Arai, E. and Kubo, T., 3D shape prediction of a paper model of a brassiere cup toward its design support -1 st report: Application to a two piece brassiere cup-, Journal of Textile Engineering, Vol. 65, No. 3(2019), pp. 35-46 (in Japanese).

Yoshida, K., Wakamatsu, H., Morinaga, E., Arai, E., Tsutsumi, S. and Kubo, T., Pattern shape optimization of a two-piece brassiere cup to improve its design efficiency, Transactions of the Institute of Systems, Control and Information Engineers, Vol. 32, No. 5(2019), pp. 192-202. 